\title{
AOS TAMBORES, AS MARGENS: AS CASAS DE RELIGIÕES DE MATRIZES AFRO- BRASILEIRAS NA MICRORREGIÃO DE CATAGUASES
}

\author{
Inácio Manoel Neves Frade da Cruz \\ Universidade do Estado de Minas Gerais/UEMG \\ inacio.cruz@uemg.br
}

\begin{abstract}
RESUMO
Este texto tem como propósito oferecer uma visão panorâmica sobre as religiões de matrizes afrobrasileiras em quatro municípios pertencentes à microrregião de Cataguases/MG. O trabalho foi construído a partir das visitas às casas de religiões e da consulta a acervos públicos municipais, livros e sites vinculados às cidades pesquisadas. Pretende-se ocupar uma lacuna referente à produção do conhecimento sobre crenças alternativas, sobretudo, em relação às denominações evangélicas e católica. A possibilidade de desconstruir estereótipos e dar a conhecer alguns templos de umbanda e candomblé nas localidades estudadas, bem como a permanência dos casos de intolerância religiosa contra as suas lideranças e frequentadores, foram questões que motivaram esta pesquisa.
\end{abstract}

Palavras-chave: Religião de matriz afro-brasileira. Intolerância religiosa. Microrregião de Cataguases.

\section{TO THE DRUMS, THE MARGINS: THE HOUSES OF RELIGIONS OF AFRO- BRAZILIAN MATRICES IN THE MICRO-REGION OF CATAGUASES}

\begin{abstract}
This text aims to offer a panoramic view on the religions of Afro-Brazilian matrices in four municipalities belonging to the Cataguases/MG micro-region. The work was built from visits to religious houses and consultation with municipal public collections, books and websites linked to the cities surveyed. It is intended to fill a gap regarding the production of knowledge about alternative beliefs, especially in relation to evangelical and Catholic denominations. The possibility of deconstructing stereotypes and making known some temples of umbanda and candomble in the locations studied, as well as the permanence of cases of religious intolerance against their leaders and regulars, were issues that motivated this research.
\end{abstract}

Keywords: Afro-Brazilian matrix religion. Religious intolerance. Cataguases micro-region.

\section{A LOS TAMBORES, LOS MÁRGENES: LAS CASAS DE LAS RELIGIONES DE MATRICES AFROBRASILEÑAS EN LA MICRORREGIÓN DE CATAGUASES}

\section{RESUMEN}

El objetivo de este texto es ofrecer una vista panorámica de las religiones de las matrices afrobrasileñas en cuatro municipios pertenecientes a la microrregión de Cataguases/MG. El trabajo se construyó a partir de visitas a casas religiosas y consultas con colecciones públicas municipales, 
libros y sitios web vinculados a las ciudades encuestadas. Se pretende llenar un vacío con respecto a la producción de conocimiento sobre creencias alternativas, especialmente en relación con las denominaciones evangélicas y católicas. La posibilidad de deconstruir estereotipos y dar a conocer algunos templos de umbanda y candomblé en los lugares estudiados, así como la permanencia de los casos de intolerancia religiosa contra sus líderes y clientes habituales, fueron temas que motivaron esta investigación.

Palabras clave: Religión de la matriz afrobrasileña. Intolerancia religiosa. Cataguases microrregión.

\section{AUX TAMBOURS, AUX MARGES: LES MAISONS DES RELIGIONS DE MATRICES AFRO-BRESILIENNES DANS LA MICROREGION DES CATAGUASES}

\section{RÉSUMÉ}

Ce texte vise à offrir une vue panoramique sur les religions des matrices afro-brésiliennes dans quatre communes appartenant à la micro-région des Cataguases/MG. L'œuvre a été construite à partir de visites de maisons religieuses et de consultations avec des collections publiques municipales, des livres et des sites Web liés aux villes étudiées. Il vise à combler une lacune concernant la production de connaissances sur les croyances alternatives, en particulier en ce qui concerne les dénominations évangéliques et catholiques. La possibilité de déconstruire les stéréotypes et de faire connaître certains temples de l'Ombanda et du Candomblé dans les lieux étudiés, ainsi que la permanence des cas d'intolérance religieuse contre leurs dirigeants et habitués, ont été des enjeux qui ont motivé cette recherche.

Mots clés: Religion de matrice afro-brésilienne. Intolérance religieuse. Microrégion des cataguases.

As 'culturas' não posam para fotografias. As tentativas de fazê-las posar sempre envolvem simplificações e exclusões, a seleção de um foco temporal, a construção de uma relação eu-outro específica e a imposição ou a negociação de uma relação de poder.

James Clifford (2016, p. 42)

\section{INTRODUÇÃO}

"A macumba invade Cataguases. E a polícia vai 'estourar' estes centros de feitiçaria e prostituição. Esta reportagem volta a alertar os malandros, pais de santo, mães de santo e caterva que se acautelem, pois em 'cana' vão entrar [...]”. Escritas em letras garrafais, as frases dessa manchete do jornal Correio da Cidade $^{1}$ ajudam a revelar pelo menos dois aspectos do campo

\footnotetext{
${ }^{1}$ Conferir o jornal Correio da Cidade, 07 de setembro de 1968, p. 6.
} 
religioso do município de Cataguases (MG), na segunda metade do século XX. O primeiro, oferece pistas sobre a intensidade da prática das religiões de matrizes afro-brasileiras e, como veremos adiante, pode sugerir uma certa intimidade dos moradores da localidade, aí incluída a elite, com os Exus, Pretos Velhos e Caboclos. O segundo, diz respeito à concepção e tratamento por parte de um segmento da imprensa sobre os adeptos da umbanda, vista por eles como macumba. Com a clara intenção de intimidar pais e mães de santo em relação ao seu sacerdócio, autorizado ou não, o jornal operava como porta-voz de um aparelho repressor do Estado, isto é, da Polícia Militar/MG.

A perversa compreensão de mundo que alimentava com esse tipo de conteúdo as colunas dos periódicos presentes na Zona da Mata/MG, é a mesma que silenciava e tornava quase imperceptíveis os rituais pontuados por signos que, entrelaçados ao imaginário cristão, remetem à cultura indígena e africana. Acionadas por indivíduos das mais disparatadas origens, tais religiosidades se tornaram mobilizadoras de redes de aconselhamento, cura e terapias alternativas, pontuadas por uma gramática africana geradora de uma memória coletiva compartilhada às escondidas na região. Quanto à legitimidade do ato da cura, essas medicinas paralelas (LAPALANTINE; RABEYRON, 1989), que diluem mediunidade e fitoterapia no processo de compreensão e combate ao infortúnio, ${ }^{2}$ foram duplamente desautorizadas: pelo saber científico, representado pela medicina alopata e pelos representantes de religiões cristãs, tais como o catolicismo e o espiritismo kardecista.

Com o escopo de preencher uma lacuna no âmbito das pesquisas sobre religião em municípios da Zona da Mata mineira, o propósito deste estudo foi penetrar e dar a conhecer o universo sagrado afro-brasileiro em quatro cidades da microrregião de Cataguases, ${ }^{3}$ com base na leitura de jornais ${ }^{4}$, em sites de notícias ${ }^{5}$ e no mapeamento das casas religiosas situadas nas cidades

\footnotetext{
2 No livro "Da doença à desordem: a magia na umbanda", a antropóloga Paula Montero (1985) trata das experiências terapêuticas constituídas no âmbito dos terreiros. Compreendido como integrante de uma medicina alternativa, o repertório de práticas curativas da umbanda faz pensar na interpretação das moléstias com base numa perspectiva mágico-religiosa.

${ }^{3}$ A microrregião de Cataguases é uma das sete unidades formadoras da mesorregião da Zona da Mata/MG e é composta por quatorze municípios, quais sejam: Além Paraíba, Argirita, Cataguases, Dona Eusébia, Estrela Dalva, Itamarati de Minas, Laranjal, Leopoldina, Palma, Pirapetinga, Recreio, Santana de Cataguases, Santo Antônio do Aventureiro e Volta Grande.

${ }^{4}$ Para esta pesquisa foram lidos os jornais Cataguases (de 1906 a 1990), Evolução (1914-1916), Correio da Cidade (1966-1974), Gazeta de Leopoldina (1896-1990), O Dia (1959) e Tribuna da Mata (1967-1969).

5 Especificamente os endereços eletrônicos "Site do Marcelo Lopes" e "Mídia Mineira", de Cataguases e "O Leopoldinense" e "O vigilante on line", de Leopoldina.
} 
de Leopoldina, Cataguases, Recreio e Argirita. ${ }^{6}$ De modo categórico, a visão que vem desqualificando sobretudo os cultos umbandistas e candomblecistas, e, em menor escala, os agentes autônomos, ${ }^{7}$ transbordou dos veículos jornalísticos e, pedagogicamente, se amalgamou no imaginário de praticamente todos os segmentos sociais presentes nas referidas localidades.

O recorte temporal alargado (da última década do século XIX ao tempo presente) foi um dos procedimentos adotados para realçar fatos pontuais de uma história da religiosidade afrodescendente que não consta em livros didáticos. Entremeado com informações presentes nos jornais locais e em livros produzidos na região, o texto não se prende a uma linha temporal progressiva, podendo em certas passagens avançar até a atualidade e, logo após, recuar algumas décadas. Do cruzamento entre os dados produzidos com base nas visitas aos centros, nas entrevistas semiestruturadas, ${ }^{8}$ nos surveys respondidos pelas(os) dirigentes das casas e nas matérias jornalísticas recortadas da mídia regional, deriva a compreensão de um contexto capaz de permitir que pequenos coletivos possam dominar imensos coletivos. O estar em campo foi precedido por uma discussão a respeito da possibilidade do encontro entre múltiplos saberes, em que o cuidado para não sobrepor uns aos outros é condição metodológica primordial. Tal reflexão segue o raciocínio de George Marcus (2004, p. 150), quando afirma que os projetos de etnografia se inserem nos ambientes de pesquisa de campo por meio de uma série de "[...] áreas de conhecimentos colaterais [...] os quais não pode ignorar ao abrir seu caminho em direção às cenas preferidas da vida comum [...] com as quais, tradicionalmente, está à vontade”. Marcus (2004) ainda nos alerta para a necessidade de fazer do próprio lugar parte do plano de investigação da pesquisa de campo.

\footnotetext{
${ }^{6}$ A proximidade espacial, os antecedentes históricos que ligavam os três municípios a Leopoldina e as estreitas relações de vizinhança foram os critérios para a escolha dos ambientes pesquisados.

${ }^{7}$ Compreendo por agentes autônomos, os indivíduos iniciados na umbanda ou no candomblé e que trabalham sem vínculos com os terreiros locais. Geralmente, atendem em um cômodo localizado em sua própria moradia e possuem uma clientela regular, porém individualizada. Não realizam sessões com data e hora marcadas e abertas ao público. Ao contrário dos terreiros, a quase totalidade não trabalha com desenvolvimento mediúnico de terceiros nem possui qualquer natureza de registro ou vínculo institucional com federações e outras entidades do tipo. Por fim, os agentes autônomos não devem ser confundidos com os benzedeiros ou benzedeiras, como é o caso da quase centenária "Dona Roxinha", uma das mais tradicionais conhecedoras da arte da benzedura estabelecidas em Leopoldina.

${ }^{8}$ Algumas entrevistas acima mencionadas foram gravadas em vídeo e, junto com imagens das sessões (jiras ou giras), compuseram parte do conteúdo de um filme documentário, lançado em 2016, intitulado "Firma o guia povo de santo", produzido pela equipe do Mapeamento das casas de religiões de matrizes africanas em municípios da microrregião de Cataguases - MG, tendo participado, entre outros, do $7^{\circ}$ Festival Internacional de Filme Etnográfico do Recife e do $15^{\circ}$ Cine Amazônia - Festival Latino-Americano de Cinema Ambiental. Para acessar o documentário, conferir o link: https://www.youtube.com/watch?v=WNZxvyaqN9o
}

Rev. Iberoam. Patrim. Histórico-Educativo, Campinas (SP), v. 6, p. 1-24, e020008, 2020. 
O banco de dados produzido pelo projeto Mapeamento das casas de religiões de matrizes africanas em municípios da microrregião de Cataguases - $M G,{ }^{9}$ constitui-se por centenas de registros fotográficos alusivos aos espaços rituais e aos atores sociais envolvidos nas práticas espirituais. Além dos diálogos informais estabelecidos em todas as células religiosas visitadas, cujo principal conteúdo encontra-se memorizado em caderno de campo, foram efetuadas perguntas pontuais que trataram das datas de fundação das casas de matrizes afro-brasileiras na região; da formação escolar dos sacerdotes e sacerdotisas; dos números absolutos de adesão da população a cada uma das células religiosas; do tipo de ritual, festas e as entidades presentes em cada um dos locais visitados; da intolerância religiosa. Até o momento foram registradas duas casas de umbanda em Argirita; trinta e oito casas de umbanda, uma de candomblé e quatro agentes autônomos em Cataguases; vinte e seis casas de umbanda, uma de umbanda/pajelança, duas de candomblé e doze agentes autônomos em Leopoldina; seis casas de umbanda, duas de candomblé e quatro agentes autônomos em Recreio.

Compreendo as tradições religiosas, não com a ilusão de as congelar no tempo/espaço, mas para pensá-las como instrumento de transformação e desenvolvimento social e, não menos, como possibilidade de uma parcela do povo se afirmar em sua própria cultura (D’ADESKY, 2009). Compostas a partir do alinhavo entre diversas tradições mágico-religiosas, inclusive a indígena, a maior parte das casas reconhecidas como de matrizes afro-brasileiras, não ficou imune em seu histórico de legitimação, como salientou Renato Ortiz (1988) quando tratou do processo de embranquecimento ou cristianização da umbanda. Os espaços sagrados apresentados neste estudo são marcados por uma relativa diversidade étnica, com a ressalva das imprecisões associadas ao termo, ${ }^{10}$ quanto aos especialistas religiosos e maior ainda em relação aos consulentes. Longe de estarmos em contato com terreiros pautados pela busca incessante por uma essência africana, num movimento de descolonização das influências cristãs e muçulmanas, estamos frente a frente a religiões bem ajustadas às conexões dos tempos modernos (PIERUCCI, 2006).

\footnotetext{
${ }^{9}$ Entre os anos de 2009 e 2011 coordenei um projeto de pesquisa intitulado "O sagrado e o profano na terra da arte: mapeamento das religiões no município de Cataguases - MG". O empreendimento contou com a colaboração de alunos da graduação em História das Faculdades Integradas de Cataguases - FIC e do curso de Direito da Faculdade Sudamérica. Esse trabalho foi incorporado a outros três projetos de pesquisa (mapeamentos) desenvolvidos posteriormente na Universidade do Estado de Minas Gerais/Unidade Leopoldina, todos apoiados por editais do Programa Institucional de Apoio à Pesquisa da UEMG/PAPq.

${ }^{10}$ Sobre as imprecisões em torno da noção de etnicidade, conferir: POUTIGNAT, Philippe; STREIFF-FENART, Jocelyne. Teorias da etnicidade. São Paulo: Ed. UNESP, 2011.
} 
Marco Aurélio Luz (2011) afirma que no sentido oposto em relação a certas denominações cristãs, a religião dos negros passou longe de ser o "ópio do povo". Ao contrário, o sagrado de coloração africana é fundamental, “[...] é fonte de afirmação dos valores civilizatórios negros e núcleo de resistência às variadas formas de aspirações neocolonialistas" (LUZ, 2011, p. 68). Renato Ortiz (1999), em “A morte branca do feiticeiro negro", salienta as condições desfavoráveis do negro antes e depois da abolição. Inclusive, na pós-abolição a competição com o imigrante europeu continuou a empurrar o afrodescendente em direção às margens da sociedade. Segundo o autor, a "macumba aparece pois como um esforço da comunidade negra e mulata para se dar um cosmo simbólico coerente diante da incoerência da sociedade." (ORTIZ, 1999, p. 30). Para Ortiz, a umbanda exprime por intermédio de seu universo religioso, o movimento de consolidação de uma sociedade urbano-industrial, uma vez que "[...] A umbanda não é uma religião do tipo messiânico, que tem origem bem determinada na pessoa do messias, pelo contrário, ela é fruto das mudanças sociais que se efetuam numa direção determinada." (ORTIZ, 1999, p. 32).

A trajetória deste estudo abrange outros três tópicos. O primeiro trata do vácuo de estudos, voltados para o contexto regional, a respeito das formas de crer dos afrodescendentes e também da disseminação de informações imprecisas e inidôneas por parte da mídia. Em seguida, são tecidas características pontuais do campo religioso de matrizes afro-brasileiras das quatro cidades pesquisadas. Neste item, damos a conhecer um pequeno percentual das casas de umbanda e candomblé estabelecidas nas localidades em pauta. Nas considerações finais, retomo algumas questões primordiais relacionadas ao universo religioso alternativo ao modelo cristão.

\section{O RACISMO EPISTEMOLÓGICO}

Especificamente sobre as práticas religiosas de matrizes afro-brasileiras, o saber que norteia a conduta ordinária no dia a dia e orienta o mundo da vida cotidiana (BERGER; LUCKMANN, 2008) não se conformou sem a marca dos estereótipos que associavam seus praticantes a pessoas socialmente e moralmente desclassificadas. Conexa ao vácuo de informações que contribui para desmanchar identidades, a ideia de racismo epistemológico trata da distorção ou da inexistência proposital de conhecimento produzido a respeito de determinados grupos sociais. Assim como Renato Ortiz (1999), ao salientar o descaso com os descendentes de africanos nascidos no Brasil, antes e pós-abolição, Abdias do Nascimento (1978) questiona o lugar da história da África nos 
bancos escolares em todos os níveis do ensino e aponta para o fato de a educação figurar na estrutura dos racismos culturais. Segundo o estudioso, a cultura africana jamais poderia ser qualificada enquanto folclore, pois estaria sujeita a se tornar "instrumento mortal no esquema de imobilização e fossilização de seus elementos vitais" (NASCIMENTO, 1978, p. 119). Defensor da necessidade de promover uma reforma na concepção e composição da educação brasileira, o professor considerava que:

O sistema educacional é usado como aparelhamento de controle nessa estrutura de discriminação cultural. Em todos os níveis do ensino brasileiro - elementar, secundário, universitário - o elenco das matérias ensinadas [...] constitui um ritual da formalidade e da ostentação da Europa, e, mais recentemente, dos Estados Unidos. Se consciência é memória e futuro, quando e onde está a memória africana, parte inalienável da consciência brasileira? Onde e quando a história da África, o desenvolvimento de suas culturas e civilizações, as características de seu povo, foram ou são ensinadas nas escolas brasileiras? (NASCIMENTO, 1978, p. 95).

Em que pese a luta política de Abdias do Nascimento em prol das mesmas, em certo sentido, poderíamos responder aos questionamentos apontando para a luz no fim do túnel que se acendeu com as leis 10.639/03 e 11.645/08. Entretanto, ao fechar o foco no material didático e paradidático disponível no meio educacional foi constatado que inexistem publicações a respeito das inúmeras contribuições de negros e índios para as práticas religiosas populares das cidades pesquisadas. Da Educação Infantil ao Ensino Médio, caso os estudantes afrodescendentes - ou outros quaisquer desejem conhecer algo a respeito dos costumes e da espiritualidade dos seus ancestrais que por ali viveram, não encontram nenhum estudo produzido com essa finalidade. Por quase todo o século $\mathrm{XX}$, as raras fontes escritas que fazem menção aos praticantes locais das religiões afro-brasileiras se encontram nos jornais editados nas pequenas cidades, como é o caso do Cataguazes e da Gazeta de Leopoldina, semanários publicados respectivamente nos municípios de Cataguases e Leopoldina.

A propósito da ausência das religiões de matrizes africanas e também dos afrodescendentes e remanescentes dos indígenas em materiais de estudo disponíveis nas bibliotecas escolares locais, um dos livros mais requisitados é Cataguases Centenária: Dados para sua história (1977), escrito pelo memorialista Levy Simões da Costa. Logo nas primeiras páginas, encontra-se um item informando como era o município na época de sua inauguração (1877), contendo o número de casas, ruas praças, médicos, advogados, vigário, professor público, enfim, tudo somado, segundo 
o autor, a localidade computava 450 habitantes. Porém, nesse cálculo só foram contados os indivíduos brancos. Caso o contingente de escravizados merecesse a atenção do leitor, certamente o número de habitantes deveria ser bastante superior aos 450 moradores. Para esconder essa parcela do povo, apequenava-se a cidade. Ao folhear mais algumas páginas, deparamos com o capítulo dois, que nos interessa mais de perto: Religião. Em seu estudo do campo religioso, Levy Simões só conseguiu enxergar os templos católicos, os centros espíritas (kardecistas) e, espremidas em pouco mais de duas páginas, as igrejas evangélicas. É como se os atabaques nunca tivessem ressoado e os cultos afro-brasileiros não existissem numa Cataguases eminentemente marcada pela beatice das suas conservadoras famílias. Vale sublinhar que a obra foi publicada em 1977, portanto, como veremos adiante, duas décadas depois da fundação da Tenda Espírita Filhos de São Jerônimo e oito anos após a fundação do Centro de Umbanda Maria Quitéria, conforme indica sua ata de instalação.

Se alterarmos o enfoque para Leopoldina, a situação de esquecimento não difere em nada quando o assunto é a religiosidade afro-brasileira. Observemos o livro didático Uma viagem no tempo - Leopoldina: povoamento, café e atualidades, de autoria de Lucilene Nunes da Silva e Natania Aparecida da Silva Nogueira, direcionado ao 4. ${ }^{\circ}$ ano do Ensino Fundamental, em atenção às exigências da Lei 3.657/2005, que dispõe sobre a inserção da disciplina "História do Município" na matriz curricular das escolas municipais em Leopoldina. A Parte III (intitulada "Quem trabalha em Leopoldina?") é composta pelo item 3.1 - O escravo, cujo espaço seria apropriado para tratar dos hábitos religiosos do referido grupo. Contudo, o que se percebe é a ênfase no grande contingente relativo à escravaria que se ocupava do cultivo dos cafezais. ${ }^{11}$ Além disso, sobressai uma pintura de Jean-Baptiste Debret [1768-1848] de um escravo jogado ao chão, com as mãos imobilizadas por um pedaço de pau, sendo humilhado e castigado, seguida de um parágrafo com o seguinte teor: "Quando não trabalhavam direito, podiam ser castigados de forma cruel, com chicotadas e surras" (SILVA; NOGUEIRA, 2008, p. 47) (grifo meu). Recorro novamente a Abdias do Nascimento e sua crítica sobre a tendência a folclorizar culturas consideradas exóticas (em relação ao modelo eurocêntrico), uma vez que a temática afro-brasileira se situa no capítulo

\footnotetext{
${ }^{11}$ Segundo Nogueira e Silva (2007), o município de Leopoldina, em decorrência de sua histórica vocação agrícola, por algum tempo, abrigou um dos maiores contingentes de população escrava de Minas Gerais. No ano de 1872, sua porção territorial detinha a maior escravaria da Província, com 15.253 elementos. Na década em que sucedeu a abolição do cativeiro no Brasil, por exemplo, no ano de 1883, a localidade defendia o posto de segunda cidade com maior número de escravos da Província, com 16.001 indivíduos, contra 21.808 da primeira colocada, a cidade de Juiz de Fora.
} 
referente à cultura popular, especificamente no subitem intitulado "Nosso folclore e tradições". Afora isso, ainda no item 3.1 ganha destaque a figura de um antigo morador da região, José Jeronymo de Mesquita, o Barão do Bonfim, por sua hipotética benevolência com os cativos e por ter alforriado 182 deles em 15 de abril de 1888, ou seja, menos de trinta dias antes da abolição da escravatura, em 13 de maio de 1888. Fica a ressalva: não tenho a pretensão de desmerecer o trabalho das colegas. Porém, mesmo reconhecendo ser uma publicação relevante para a localidade, pontuada com fotografias, gravuras e quadrinhos, o que sugere um aspecto lúdico, é importante ressaltar que não será com essa leitura que a criança poderá despertar sua curiosidade em saber como os seus prováveis antepassados lidavam com o universo sagrado que não fosse essencialmente cristão.

Até os anos 1970, as parcas informações sobre os antigos praticantes das religiões afrobrasileiras, regra geral, só costumavam ser localizadas nas Colunas Policiais, espaço em que apareciam os personagens associados às práticas dos canjerês, calundus, batuques e macumbas. ${ }^{12}$ Só a partir de 1972 foi encontrada a primeira notícia em um jornal da região com um teor que não fosse acusatório. ${ }^{13}$ Trata-se de um pequeno texto sobre a festa natalina promovida pela "Escolinha Cabocla Jupira”, vinculada ao Centro Espírita de Umbanda Maria Quitéria, situado em Cataguases e fundado em 02 de junho de 1969. Após a leitura detalhada, principalmente, dos jornais "Cataguases" e "Gazeta de Leopoldina", foram assinaladas apenas mais onze matérias sem o contumaz teor depreciativo a respeito das religiões de matrizes afro-brasileiras, sendo que, oito delas diziam respeito ao referido centro, fato que sugere certa proximidade de um editor do jornal, no período em questão, com Manoel Luchini Ribeiro, então presidente da casa Maria Quitéria. ${ }^{14}$ Como resposta a tal situação, uma das alternativas é a construção e divulgação no meio educacional de um conhecimento alternativo em relação a essas visões estigmatizadas que inundam o senso comum. Ao se despir dos estereótipos a eles associados, esses saberes se tornam capazes de

\footnotetext{
${ }^{12}$ Associados à feitiçaria e bruxaria, canjerê, cabula, calundu e macumba são alguns dos termos empregados no século XIX e na primeira metade do XX para designar as práticas religiosas de matrizes afro-brasileiras.

${ }^{13}$ Conferir a primeira página do jornal Cataguases, 01 de janeiro de 1972.

14 Todas as onze matérias foram encontradas no jornal Cataguases, cobrindo um período que vai de 01 de janeiro de 1972 a 06 de abril de 1980. São três balancetes anuais referentes ao C. E. de Umbanda Maria Quitéria, dando a conhecer a receita e as despesas da casa, quatro notícias sobre a construção e inauguração da nova sede do centro e uma mensagem de Feliz Natal e Próspero Ano Novo. As outras três notícias restantes, tratam da: a) morte do Dr. Antonio Troisi, considerado grande benfeitor do Centro Espírita de Umbanda Índio Pena Branca - a Caminho da Verdade (atualmente extinto), em 05 de outubro de 1975; b) formação da diretoria do Centro de Umbanda Amor e Caridade (já extinto), em 15 de novembro de 1975; c) inauguração do Centro de Umbanda Pai Jacó, em 22 de outubro de 1978 (também já extinto).
}

Rev. Iberoam. Patrim. Histórico-Educativo, Campinas (SP), v. 6, p. 1-24, e020008, 2020. 
promover novos olhares sobre a cultura africana, reverberando nos processos de construção de identidade e, por conseguinte, na experiência de socialização entre nossos educandos.

Em nível regional, já no século XXI, observa-se o declínio e quase desaparecimento dos jornais semanais impressos, ao passo em que ocorre a transferência das redes de notícias para a internet. Todavia, o padrão "invisibilidade"15 continua a rondar a pauta dos canais de notícias regionais, isto é, escusado o cantinho cativo no território das "Ocorrências Policiais", as religiões de matrizes afro-brasileiras praticamente não são citadas, senão indiretamente em matérias alusivas a grupos de caxambu, dança ou capoeira, por exemplo. Ainda hoje, aquele teor persecutório e de menoscabo com os signos de ordem africana, continua presente nos canais de notícias mais acessados na região.

Algumas décadas depois das manchetes agressivas do jornal Correio da Cidade, em 27 de setembro de 2014, o Site do Marcelo Lopes: notícias de Cataguases e região cravava o seguinte título em um dos textos jornalísticos por ele veiculados: "Macumba pode ter sido a causa de mais um incêndio em Cataguases" (grifo meu). Fartamente ilustrada com fotografias do local do suposto início da queimada, com ênfase na aguardente e nas velas pretas e vermelhas, a matéria dava voz a acusação de quatro sitiantes vizinhos ao incêndio e (des)informava: "[...] o que provocou a queimada teria sido um despacho ou oferenda ao orixá Exu, popularmente conhecido como 'macumba', conforme mostram as fotos que ilustram esta reportagem". (sic) ${ }^{16}$ Não cabe aqui advogar em defesa do(a) autor(a) da oferenda a Exu, todavia, a referida peça jornalística ao atribuir à macumba a razão de um incêndio, novamente enquadrava os(as) praticantes das religiões de matrizes afro-brasileiras no rol dos marginais. Fosse a guimba de um cigarro descartado por descuido por um filho(a) ou neto(a) de algum dos proprietários rurais vizinhos a causa do incêndio, e, certamente não teríamos a matéria acusatória.

Tragédias como acidentes automobilísticos com vítimas fatais e homicídios são assuntos que pontuam as agendas dos veículos de notícias regionais. Assim, no dia 10 de fevereiro de 2017,

\footnotetext{
15 Amparado em Reginaldo Prandi (2007), é interessante relativizar essa invisibilidade. Segundo o sociólogo da religião, tanto o candomblé como a umbanda ao serem associados como integrantes da cultura nacional, contribuíram para a composição da identidade brasileira, tornando-se, obviamente, conhecidos em toda nação. Porém, no caso específico da maior parte dos espaços visitados no mapeamento, a invisibilidade diz respeito a uma tendência de algumas lideranças religiosas em dissimular os espaços rituais (geralmente situados nos fundos de uma residência) com o objetivo de evitar conflitos com a vizinhança intolerante. A ausência de placas indicativas (como é comum nos templos evangélicos) é mais um dos indicativos dessa invisibilidade.

16 Conferir: http://www.marcelolopes.jor.br/noticia/detalhe/16107/macumba-pode-ter-sido-a-causa-de-mais-umincendio-em-cataguases.
}

Rev. Iberoam. Patrim. Histórico-Educativo, Campinas (SP), v. 6, p. 1-24, e020008, 2020. 
o assassinato de um jovem ganhou as manchetes dos sites Mídia Mineira e O vigilante on line ${ }^{17}$ Até aí tudo dentro do padrão jornalístico local, não fosse a coincidência entre as duas matérias ao apontar a alcunha da vítima: "Macumba". Inclusive, quando a Polícia Civil de Leopoldina conseguiu capturar um dos supostos autores do crime, já em 29 de março de 2017, tal fato também foi noticiado, agora apenas no site Vigilante on line que apresentou as iniciais do assassino, tratando-o como "suspeito de homicídio praticado no final da noite do dia 10 de fevereiro, vitimando Evaldo Antônio Lima Junior, conhecido como 'Macumba', de 22 anos" (grifo meu). Novamente, o jovem - segundo o site Mídia Mineira, já conhecido no meio policial - teve sua identidade marcada a ferro e fogo com base em uma suposta predileção a um culto religioso afrobrasileiro que, certamente, não poderia ser a "macumba", ${ }^{18}$ uma vez que não se tem notícias de templos de macumba, e, sim de terreiros de umbanda, candomblé, etc. Teria sido revelado, fosse o apelido da vítima "Val", "Dinho" ou outro qualquer que o valha?

\section{OS MUNICÍPIOS PESQUISADOS: CATAGUASES, LEOPOLDINA, ARGIRITA E RECREIO}

Comparadas com os outros municípios componentes da microrregião em questão, Cataguases e Leopoldina são as cidades que concentram maior contingente populacional. ${ }^{19}$ Ao longo de suas histórias, ambas vêm tentando construir uma marca identitária pontuada por associações com o mundo das letras e das artes, tendo como ponto de apoio personalidades históricas que nasceram ou viveram em seu território. Em linhas gerais, enquanto Leopoldina se agarra ao poeta paraibano Augusto dos Anjos [1884-1914], intitulando-se a Athenas da Zona da Mata, Cataguases granjeia visibilidade com Humberto Mauro [1897-1983] e acredita ser o Berço do Cinema Brasileiro. A arquitetura modernista é outro elemento a legitimar o bordão Cataguases: Museu a céu aberto. Em suma, cinema e literatura as orientam em direção ao futuro e nunca saem

17 Conferir: http://www.midiamineira.com/2017/02/jovem-e-assassinado-tiros-em-leopoldina.html e https://www.ovigilanteonline.com/noticia/detalhe/34957/policia-civil-de-leopoldina-prende-suspeito-de-matarjovem-com-dois-tiros-no-trevo-do-alto-do-cemiterio.

${ }^{18}$ Para além do aspecto pejorativo carreado na palavra macumba, cabe esclarecer que o vocábulo, segundo o Dicionário Eletrônico Houaiss, diz respeito a um "antigo instrumento de percussão de origem africana, que era outrora usado em terreiros de cultos afro-brasileiros".

${ }^{19}$ Segundo estimativa do IBGE, para o ano de 2015, Cataguases e Leopoldina possuíam, respectivamente, 74.171 e 53.145 habitantes. Além Paraíba, situa-se em terceiro lugar, com 35.321 habitantes. 
da pauta dos principais empreendimentos culturais circunscritos à iniciativa privada e ao poder público.

$\mathrm{Na}$ perspectiva diacrônica, essas unidades territoriais estão inseridas num ambiente castigado pela derrubada da Mata Atlântica ${ }^{20}$ para o cultivo e comercialização em larga escala do café. Sobretudo a partir dos fins do século XVIII e início do XIX, a ocupação se deu com base no latifúndio monocultor que funcionava apoiado na exploração da mão de obra escrava. Essenciais para a produção de riquezas, os cafezais acabaram por invadir terras anteriormente habitadas por grupos indígenas. Para tornar a região mais atrativa, foi necessário levar a cabo o controverso processo ora de extermínio, ora de conversão dos nativos, fato que culminou na supressão das comunidades indígenas, especialmente, os grupos Puri e Coroado. ${ }^{21}$ Nesse espaço, teve lugar uma sociedade acentuadamente desigual, cujos valores sagrados, compartilhados pelos remanescentes de africanos e indígenas, foram duramente marginalizados. Do ponto de vista da organização econômica, sobressaem os empreendimentos no setor secundário em Cataguases, enquanto Leopoldina ainda hoje mantem acesa sua tradição ruralista. Antigos povoados pertencentes ao município de Leopoldina, Argirita e Recreio, juntos, contam com pouco mais de 12 mil habitantes e, do ponto de vista cultural, ainda hoje possuem seus hábitos intimamente ligados ao seu núcleo inicial.

Pelo menos desde os anos 1950, pode-se afiançar que as primeiras lideranças a ocupar a região registraram, junto a órgãos oficiais, tendas de espiritismo de umbanda. ${ }^{22}$ Em números absolutos, os terreiros de umbanda superam de longe os de candomblé e, por conseguinte, se apresentam como as tradições religiosas majoritárias na microrregião. Sob a perspectiva de sua distribuição espacial, a quase totalidade dos templos se encontra estabelecida no perímetro urbano dos municípios pesquisados. Ainda que existam poucas unidades na porção mais central de

\footnotetext{
${ }^{20} \mathrm{O}$ historiador norte-americano Warren Dean autor de um dos primeiros trabalhos de história ambiental no Brasil, salienta a destruição do bioma da Mata Atlântica sob uma perspectiva histórica. A propósito da referida obra, conferir: DEAN, Warren. A ferro e fogo: a história e a devastação da Mata Atlântica brasileira. São Paulo: Companhia das Letras, 1996.

${ }^{21}$ Sobre os grupos indígenas que habitavam o território mineiro, saliento dois trabalhos de diferentes metodologias e épocas: a) JOSÉ, Oiliam. Indígenas de Minas Gerais. Belo Horizonte: Itatiaia, 1965; b) OLIVEIRA, A. P. P. Loures de. (Org.). Arqueologia e Patrimônio de Minas Gerais. Juiz de Fora: Editar, 2007.

${ }^{22}$ Os espaços sagrados de matrizes afro-brasileiras costumam ser reconhecidos por diversas designações, inclusive, não há consenso entre as lideranças religiosas. Assim, ao longo da pesquisa de campo, foram anotadas as seguintes nomeações: terreiro, centro (espírita), casa, tenda, roça e ilê. Deste modo, reconhecendo a legitimidade de todos as formas, optei por variar a grafia ao longo do texto sem me prender em um único designativo, supostamente mais correto.
} 
algumas cidades, ${ }^{23}$ a maior parte está difundida entre a periferia e as extensões pontuadas por moradores de baixa renda em relação aos habitantes do centro e áreas ocupadas pela classe média. Na mesma condição de espécie única, como a comunidade do Vale do Amanhecer, outro ponto fora da curva para o padrão da microrregião é a casa Ilé Ògúntè, também situada em Leopoldina. Segundo seu líder, o cabeleireiro Domingos Sebastião Alves de Mello, além da umbanda, outra atividade ali desenvolvida é a pajelança, rito que combina costumes indígenas com elementos católicos, kardecistas e de matrizes africanas.

Após o trabalho de campo, não identificamos nenhuma liderança cuja memória permitisse falar sobre os cultos religiosos afro-brasileiros antes da década de 1950. Por outro lado, as notícias escritas sobre os mais antigos praticantes de rituais terapêuticos de matriz africana na região, apontam para um escravo do Coronel Vieira ${ }^{24}$ [1829-1881], conhecido nas redondezas por Joaquim Vinagre. Esse personagem ganhou a admiração de um dos mentores da experiência literária modernista, materializada na Revista Verde, vivida por um pequeno grupo de jovens intelectuais que orbitavam Cataguases. Enrique de Resende [1896-1973], além de escritor, era neto do Coronel Vieira e teve a oportunidade de conviver, em sua infância, com o velho Joaquim Vinagre, ${ }^{25}$ a quem dedicou um poema publicado na primeira página do Jornal Cataguases.

José Doudo, ${ }^{26}$ Sergio Fernandes, ${ }^{27}$ Sebastião Arruda e sua mulher ${ }^{28}$, Euclydes Santiago, ${ }^{29}$ Raphael Gomes do $\mathrm{Amaral}^{30}$, são alguns dos personagens que compunham o campo religioso local

\footnotetext{
${ }^{23}$ Como, por exemplo, a Casa Amigos da Paz - Campos de Oxóssi e Ogum, localizada na rua Santa Filomena, porção central da cidade de Leopoldina.

${ }^{24}$ José Vieira de Resende e Silva, o Coronel Vieira, é considerado o fundador do município de Cataguases.

${ }^{25}$ Em 06 de setembro de 1959, Enrique de Resende publicou no jornal Cataguazes o poema "Joaquim Vinagre", alusivo ao curador que faleceu entre 1912 e 1913. Ao final do poema, aparece uma "Nota da Redação" dando ciência de que "Joaquim Vinagre não é uma figura de ficção, tendo sido um velho e leal servidor do Cel. Joaquim Vieira de Rezende e Silva, fundador deste município [...]”. Sobre esse tópico, conferir a primeira página do Jornal Cataguases, do dia 06 de setembro de 1959.

${ }^{26}$ Em 14 de novembro de 1909, a Secção Policial anunciava a prisão de José Doudo em consequência do seu envolvimento em Cangerês ( $\mathrm{sic}$ ).

${ }^{27}$ Em 18 de abril de 1915 o Jornal Cataguases publicava uma resposta de Sergio Fernandes (escravo libertado em 13 de maio de 1888) contra seus acusadores do Jornal Evolução, afirmando que não entendia o motivo da perseguição, uma vez que outros indivíduos também realizavam feitiçarias, evocando a ideia de curandeirismo supostamente para os seus perseguidores kardecistas.

${ }^{28} \mathrm{O}$ casal aparece nas Occorencias policiaes do Cataguases de 07 de dezembro de 1924, acusado, como José Doudo, da prática de Cangerês.

${ }^{29}$ Em 20 de janeiro de 1920, a Gazeta de Leopoldina informava que Euclydes Santiago, vulgo Xerengo, levara duas facadas de um dos convivas de um batuque na estrada que ligava Leopoldina a Cataguases.

${ }^{30}$ Acusado do exercício do baixo espiritismo e preso em flagrante enquanto oferecia atendimento ao público, Raphael Gomes foi denunciado, pelo jornal O Nacionalista, de 03 de outubro de 1937, de curandeirismo e de cooperar para um controverso político local, o Dr. Pedro Dutra Nicácio Neto. Ao conectar a figura de um suposto curandeiro ao político
} 
na primeira metade do século $\mathrm{XX}$, sobre os quais pouco sabemos a não ser sobre as perseguições policiais e, pelo que podemos supor, no convívio social, devem ter sido fatalmente arrolados para as margens. O certo é que esses especialistas religiosos não desempenhavam seus papeis sem que tivessem, especificamente naquela região, um grupo de consulentes interessados em seus serviços. Portanto, pelo menos desde o início do século XX, a proliferação desses espaços estimulou seus novos interlocutores a conhecer a linguagem dos pais e mães de santo para poder mobilizar uma série de signos e práticas sagradas que remetem ao universo cultural africano e a suas reinvenções no Brasil.

Numa tentativa de melhor conhecer e defender suas doutrinas, nas metrópoles brasileiras, ainda na primeira metade do século XX, algumas lideranças religiosas e estudiosos manifestaram o interesse no debate sobre a umbanda, tendo como importante marco histórico a realização do Primeiro Congresso Brasileiro do Espiritismo de Umbanda, ocorrido na capital e que culminou com a publicação dos trabalhos apresentados no seminário reunido no Rio de Janeiro, de 16 a 26 de outubro de 1941. Assim, ano após ano, os terreiros iam deixando de ficar circunscritos aos nichos menos privilegiados das populações urbanas e rurais. Com o passar do tempo, médicos, militares, intelectuais, artistas, empresários, funcionários da mesma corporação policial que supostamente perseguia os cultos, entre muitos outros tipos de trabalhadores, começaram a apreciar os ritos e liturgias umbandistas e as adotaram como religião que, assim como as outras de matriz cristã, tem no exercício da caridade uma de suas maiores virtudes.

Já no final da década de cinquenta do século XX, uma publicação no jornal Cataguases intitulada "Caboclo Aimoré, Tia Rita e outros...", de autoria do professor Manuel das Neves Peixoto [1914-1999], sugere uma certa intimidade por uma parte da elite cataguasense em relação às práticas religiosas de matrizes africanas. A história narrada em sua coluna envolve personagens ainda hoje conhecidos na sociedade cataguasense e permite concluir, sem margem de erro, que os rituais afro-brasileiros eram visitados por uma clientela bastante diversificada daquela coletividade. Em sua crônica, Manuel das Neves conta que o Dirceu Marinho entrara ofegante no terreiro com uma bola de futebol nas mãos e implorara à entidade Tia Rita para que ela (a bola de futebol) só entrasse no gol do Flamenguinho. ${ }^{31}$ Porém, minutos depois, quando a Tia Rita já “estava quase

Pedro Dutra, essa notícia revela não só a possibilidade de um atravessamento entre religião e política, mas, sobretudo, a reles tentativa de manchar a imagem do político ao associá-lo a um outsider.

${ }^{31}$ O Flamengo Futebol Clube (vulgo Flamenguinho), criado em 1917, constituiu-se como clube de futebol da elite e eternamente rival do Operário Futebol Clube, também fundado naquele ano. 
saindo da cabeça do médium”, eis que aparece o João Queiroz, "afobado, para desmanchar o macete do Dirceu...” Manuel das Neves confidencia também quem lhe repassou a notícia: "quem falou foi o Dr. Cardoso, um dos retardatários..." (Jornal Cataguases, 18 out. 1959).

O texto do professor Manuel das Neves Peixoto (1959) ajuda a traduzir algumas incongruências do projeto de modernidade regional que mergulha dissimuladamente na tradição ao mesmo tempo em que se reveste de um discurso inovador e vanguardeiro. Serve também para confirmar a afinidade de um intelectual oriundo da elite local com o vocabulário e, consequentemente, com os cultos afro-brasileiros. Em outra direção, mostra a força da magia para os estratos sociais mais altos da cidade que se vende como repositório de aportes científicos e ideias modernas. Vale a pena conhecer algumas das pérolas cunhadas pelo narrador:

A entidade - Caboclo Aimoré ou Tia Rita, ou Cabocla Janaína - veio de mansinho, veio gentil, era Tia Rita que vinha e começou a trabalhar na cabeça do médium. Depois, o "cambono" ia traduzindo, com segurança, toda a mensagem da entidade pela voz levemente alterada do médium. "Êxe cumo diz Êxe" [...] Um homem que não estava muito "desenvolvido" quis dar dinheiro à "médium" ou ao ogan de terra porque se sentia feliz, porque Tia Rita tinha resolvido aquele negócio... Cuidado, moço, he disseram: não fale em dinheiro aqui, Exu pode baixar e sangue pode correr. As entidades não trabalham por dinheiro... (sic). (Jornal "Cataguases", 18 out. 1959, p. 1).

Ainda sobre essa ramificação ligando a feitiçaria (sob a perspectiva de seus detratores, obviamente) ao futebol, durante o trabalho de campo, pude perceber em algumas casas religiosas, dentro dos seus espaços rituais, uma boa variedade de flâmulas, copos, bonés, bonecos, carrancas, relógios de parede e outros objetos alusivos sobretudo ao clube de futebol mais popular do país, o Flamengo. Por exemplo, no Centro Espírita Tia Maria do Bonfim, situado no bairro Marote em Cataguases e dirigido por Maria da Conceição Teixeira, num quarto reservado aos Exus e Pombajiras, ao lado das imagens, entre bebidas alcoólicas, encontra-se uma taça com o escudo do Clube de Regatas do Flamengo - CRF, tendo ainda ao seu lado três carrancas de madeira pintadas em preto e vermelho e envoltas em uma faixa alusiva ao campeonato brasileiro vencido pelo Flamengo em 1992. Já no Centro Espírita São Jorge Guerreiro, assentado no município de Argirita e liderado pela Mãe Sônia, numa divisória do barracão onde ocorrem as jiras, ao lado de uma enorme estrela do mar, encontra-se um relógio de parede com um escudo do Clube de Regatas do Flamengo, lembrando o campeonato mundial de 1981. 
Como foi mencionado anteriormente, apesar do número expressivo de casas religiosas visitadas, não consegui encontrar documentos, nem relatos de antigos praticantes, sobre a presença de alguma entidade religiosa de matriz afro-brasileira instalada na região na primeira metade do século XX. O dia 25 de abril de 1959 é a data em que consta o primeiro registro oficial de uma casa de religião umbandista na microrregião de Cataguases. Trata-se da adesão à União Nacional dos Cultos Afro-brasileiros, no Rio de Janeiro, pela Tenda Espírita Filhos de São Jerônimo, no bairro Leonardo, na cidade de Cataguases. É bastante provável que o espaço ritual já vinha sendo ocupado com esse propósito há algum tempo, sendo, portanto, um pouco mais antigo. Assim, essa deve ser considerada a mais remota célula religiosa de matriz africana, com um documento de registro escrito, em funcionamento na região.

Um fato corrobora com a ideia de que o terreiro dedicado ao orixá Xangô, já existia anteriormente à data de sua fundação oficial. Nos anos 1950, essa Tenda Espírita foi palco para um desentendimento entre o Delegado de Polícia de Cataguases e um dos integrantes da casa, o senhor Nedio Modesto da Silva. Segundo a Relação dos Sócios Fundadores da Tenda Espírita Filhos de São Jerônimo, o referido personagem cumpria na casa a função de ogã. Não por coincidência, próximo ao mês de abril de 1959, mesma época de seu registro, foram publicadas no jornal O Dia duas matérias, assinadas pelo representante legal da mencionada União Nacional dos Cultos Afrobrasileiros, Byron Torres de Freitas, em que denunciavam uma perseguição a um dos sócios fundadores daquela célula religiosa. No artigo publicado em 23 de maio de 1959, Byron fala de Cataguases como um "infeliz município" em que ocorreu o "escandaloso e inominável caso da Tenda Espírita Filhos de São Jerônimo”.

Relativamente diferente dos demais, o terreiro em questão possui todas as suas paredes ornadas com pinturas executadas, em estado de transe, pelo atual zelador ${ }^{32}$ chamado Nilo Jorge dos Reis Ramalho e conhecido como Pai Nilo. A casa ainda abriga algumas ferramentas de santo e imagens de caboclos e pretos velhos relativamente antigas, sobretudo se compararmos com a maior parte das unidades visitadas. Os documentos cedidos ao projeto dizem respeito à filiação a uma entidade jurídica localizada na cidade do Rio de Janeiro, fato que ajuda a demonstrar uma estreita ligação de cidades da Zona da Mata/MG com especialistas religiosos da metrópole. Diversos depoimentos dos dirigentes com os quais conversei estão em consonância quando estes indicam que desenvolveram suas capacidades mediúnicas em algum terreiro no Rio de Janeiro, em

${ }^{32}$ Zelador de terreiro ou zelador de santo é uma das formas como se autodenominam as lideranças religiosas. Rev. Iberoam. Patrim. Histórico-Educativo, Campinas (SP), v. 6, p. 1-24, e020008, 2020. 
alguns casos, inclusive, em casas de candomblé. Em alusão a sua passagem pelo candomblé, estes especialistas costumam ser chamados de umbandistas de cabeça raspada.

A casa religiosa de registro mais antigo no município de Leopoldina é o Centro Espírita Nosso Senhor do Bonfim. Sua fundação oficial remonta ao dia 30 de março de 1967. A divindade patrona do centro é a Vovó Rita do Cruzeiro e as sessões ocorrem aos sábados, de quinze em quinze dias. Segundo seu dirigente, Alair Morais Pires, costureiro, com curso superior incompleto, fora os consulentes, cujo número varia de sessão para sessão, participam das giras quatorze médiuns, sendo que por ocasião de nossa conversa, dois deles estavam na Alemanha e outros dois na Espanha. Uma última casa merece menção em razão da data de sua criação e por ter sobrevivido num ambiente um pouco mais distante do meio urbano. Trata-se do Centro Espírita São Jorge, que, segundo seu dirigente Francisco Vitoriano da Silva, abriga uma mesa que remonta a oitenta anos. Entretanto, a criação oficial da casa se deu no dia 30 de julho de 1969. Segundo a Ata de Fundação, o espaço ritual funcionava em uma fazenda no distrito de Conceição da Boa Vista, atualmente pertencente ao município de Recreio.

Em Argirita, o templo mais procurado é liderado por Mãe Sônia, ou Sônia dos Reis Santiago. O Centro Espírita São Jorge Guerreiro, fundado em 21 de fevereiro de 1993, ocupa uma chácara numa das extremidades da cidade. A propriedade possui espaço para o cultivo de ervas destinadas aos banhos (amacis ou amassis) purificatórios e terapêuticos, indicados tanto aos iniciados quanto aos consulentes comuns. No interior da propriedade, em uma parte de um barranco próximo à casa onde vive Mãe Sônia encontram-se quatro imagens de Malandros e Pombajiras em cavidades artificialmente esculpidas. Talvez em decorrência do pequeno número de habitantes residentes no município (2.717 indivíduos estimados em 2019) ao proceder o trabalho de campo, ficou claro o conhecimento da comunidade a respeito dos trabalhos realizados pelo terreiro de Mãe Sônia. As dimensões do barracão são relativamente grandes se comparadas com a outra casa, o Centro Espírita Caboclo Giramundo, também situado em Argirita. Seu zelador, Joviano Augusto Moreira Pereira, aposentado, com curso superior em Ciências Biológicas, informou que não se lembra com precisão, mas acredita que os trabalhos com a umbanda tiveram início em setembro de 1980.

O município de Recreio possui um campo religioso bastante peculiar e, ao contrário de outras cidades pertencentes à microrregião de Cataguases, como, por exemplo, Dona Euzébia, Santana de Cataguases e Itamarati de Minas, os rituais afro-brasileiros ainda movimentam um bom 
naco da sociedade. A distribuição espacial das unidades religiosas é bastante equilibrada em relação a todos as outras localidades visitadas. Dos oito espaços detectados, dois encontram-se na zona rural, dois no distrito de Conceição da Boa Vista e os quatro restantes na cidade. Fato que corrobora com a ideia de efervescência do campo religioso, além dos templos visitados, tivemos notícias sobre agentes autônomos que atuam regularmente e possuem clientela capaz de rivalizar com os terreiros de menor porte.

Casa de candomblé, a Tenda Espírita Boiadeiro Menino, está situada no Sítio do Serrote e é dirigida por Roberto dos Santos Jovino, o Beto Macumba como é popularmente conhecido em Recreio e na região. Bem como a Tenda Espírita Filhos de São Jerônimo, de Cataguases, a casa Boiadeiro Menino possui documento de filiação a uma entidade do Rio de Janeiro. ${ }^{33}$ Ao compararmos com todos os outros templos visitados, o espaço abriga o maior repertório de assentamentos de santo, estatuária e de ferramentas do santo. O barracão é composto por quarto de exu, um amplo salão, quarto de santo, banheiros, peji, runcó, gabinete reservado para atendimento, cozinha de santo e quintal. As giras na Tenda Espírita Boiadeiro Menino acontecem duas vezes por mês e têm início às $22 \mathrm{~h} 00$ e, segundo seu líder, nunca costumam terminar antes das 05 h00.

Em vários terreiros das quatro cidades pesquisadas escutamos os zeladores falarem na umbanda traçada, portanto, essas práticas estão presentes numa significativa porção do universo pesquisado. Quanto aos agentes autônomos, essas informações foram um pouco mais truncadas se comparadas aos diálogos com as lideranças dos centros. O que ficou relativamente patente foi uma sutil tentativa de alguns dos agentes autônomos de aproximarem suas práticas mais da benzeção do que dos rituais associados ao candomblé ou umbanda. Apenas um único agente autônomo, que atende em sua casa na rua Ismael Ávila, na cidade de Leopoldina, assumiu uma postura voltada para o exercício da quimbanda. Ele informou que presta serviços apenas com horário marcado e cobra honorários pelas consultas e trabalhos. A pouco mais de dez metros de sua casa, outro agente autônomo também disponibiliza seus préstimos. Trata-se de um irmão de sangue do indivíduo sobre o qual acabei de falar, do mesmo modo iniciado na umbanda, porém, fez questão de afirmar que nunca cobra pelos serviços e não trabalha com sacrifício de animais. Ambos possuem um pequeno cômodo reservado para os trabalhos em suas casas. São características comuns aos dois espaços a precariedade da luz e a pequena mesa, coberta com toalha e ocupada com os santos, velas e outros objetos arrolados no rito.

\footnotetext{
${ }^{33}$ A casa em questão é filiada à Confederação dos Cultos Afro-brasileiros do Estado do Rio de Janeiro.
} 
A quimbanda é um capítulo à parte em relação ao campo religioso local e suas práticas se manifestam em vários terreiros. Mesmo que nenhuma casa aponte o vocábulo quimbanda em sua denominação, alguns zeladores não se furtaram ao afirmar a intimidade com seus rituais. $\mathrm{O}$ historiador Ronaldo Vainfas (2001) ensina que "Quimbanda" é um vocábulo de origem quimbundo, idioma do tronco linguístico banto, falado na região do Congo-Angola. Vainfas afirma que a história da palavra quimbanda permite aventar a "circularidade de símbolos e costumes entre a África centro-ocidental e o Brasil, seja no domínio do erotismo, seja no tocante à religiosidade vivenciada na sociedade escravista" (VAINFAS, 2001, p. 497).

Do ponto de vista das Ciências Sociais, a quimbanda é compreendida como uma manifestação religiosa "afro-brasileira que enfatiza o culto às entidades espirituais denominadas exus e pombajiras" (TEIXEIRA, 2005, p. 9). De acordo com Talita Bender Teixeira (2005), os praticantes da quimbanda creem que os exus e pombajiras, após passagem pela Terra, podem retornar periodicamente para coexistir com os homens. Essas entidades possuem poderes suficientes para mitigar uma série de problemas e sofrimentos de seus consulentes que, com ela, estabelecem uma relação de troca de "serviços e favores". Em alguns casos, a quimbanda é vista como contraponto à umbanda de "linha branca", em outros, pode ser coadjuvante nos rituais umbandistas (TEIXEIRA, 2005), sendo também conhecida como Linha Cruzada. Para o senso comum, costuma ser associada à magia negra.

Outro importante tópico a ser abordado, também com o intento de desconstruir estereótipos, diz respeito à escolaridade das lideranças afro-brasileiras na região. Ainda que subsistam especialistas religiosos com pouco estudo, uma boa parte dos praticantes ocupou os bancos escolares pelo menos até o Ensino Médio ou foi além. Por exemplo, o Centro Espírita Amigos da Paz - Campos de Oxóssi e Ogum é dirigido por Cláudia Conte dos Anjos Lacerda, que, afora a função de sacerdotisa (Mãe de Santo) é professora e supervisora concursada e possui mestrado em Gestão e Avaliação da Educação Pública, pela Universidade Federal de Juiz de Fora. Cláudia Conte, como é chamada no meio educacional é bastante atuante na sociedade leopoldinense e, seu exemplo, contraria o senso comum quando associa os representantes das religiões afro-brasileiras a indivíduos desprovidos de maiores conhecimentos e contumazes em se esquivar do embate com os seus detratores. 


\section{CONSIDERAÇÕES FINAIS}

Na competitiva e desigual luta pela sobrevivência entre as agências religiosas no Brasil, com raras exceções, os cultos de tradição africana e indígena ocupam a esfera pública em uma posição marginal, se comparados com os católicos, kardecistas e evangélicos. Em linhas gerais, a sociedade brasileira continua produzindo várias narrativas depreciativas que, ao demonizar as práticas religiosas afro-brasileiras, acabam por intimidar suas lideranças, em diversos casos, forçando-as ainda hoje a dissimular os espaços rituais. Assim como os jornais da década de 1960, essa perspectiva enxerga os terreiros como ambientes destituídos de ética e civilidade e reprodutores de uma mentalidade mágica que já deveria estar superada pela perspectiva científica, ou no cenário político atual, suplantada pela fé e adesão a uma denominação pentecostal ou neopentecostal. Em síntese, ainda hoje a pressão social sobre os adeptos das religiões afrobrasileiras na região é tão intensa como em tempos pretéritos e se espraia na maior parte do país.

Especificamente sobre as religiões de matrizes afro-brasileiras, a antropóloga Paula Montero (2012) sugere que evitemos uma visão, pouco produtiva, em que os esquemas gerais sobre os seus ritos são tomados como qualidades essenciais e inerentes a cada culto. A autora lembra a “Marcha Contra a Intolerância Religiosa liderada por sacerdotes em 1980," e fala de uma "reação contra a violência física e moral dos Neopentecostais [na qual] líderes religiosos do Candomblé e da Umbanda se organizaram em uma frente política em defesa da 'liberdade religiosa"" (MONTERO, 2012, p. 175). Tal passagem pode ser apropriada como exemplo para o estudioso da religião não incorrer em tipologias essencialistas, como as que associam os adeptos dessas religiões a indivíduos que costumam se esquivar dos embates entre diferentes visões de mundo. A despeito da postura que procura dissimular os espaços rituais, relatada anteriormente, sabe-se que apesar do processo de absorção e trocas com o universo cristão e das mais diversificadas manobras de dominação a partir das quais o colonizador lançou mão, os afrodescendentes não aceitaram de modo submisso a coação a eles imposta. Numa palavra, o fato de "ocultar" seu ritual, pode ser compreendido como mais uma estratégia de resistência e preservação da integridade de suas práticas. Sendo assim, esse teor de invisibilidade associado aos cultos afro-brasileiros não anula a possibilidade de algumas lideranças religiosas vocalizarem uma crítica contundente em relação ao conjunto de juízos de valor e comportamentos preconceituosos direcionados aos frequentadores locais das casas de umbanda e candomblé. 
Um dos temas compartilhados por quase todos os personagens entrevistados diz respeito às atitudes de intolerância sofridas pelos praticantes das religiões de matrizes afro-brasileiras. No início do século XX, esses ataques eram capitaneados pelos católicos e, com o avanço evangélico, ganharam mais intensidade e dramaticidade no púlpito das igrejas neopentecostais. Em certos casos, como no terreiro do Beto Macumba em Recreio, percebe-se a adesão explícita à religião do santo e a propensão a não correr do embate, caso seja impelido a fazê-lo. Em outro extremo, em algumas casas, nota-se uma certa tentativa de domesticar o diálogo com os interlocutores espirituais mais outsiders (LEISTNER, 2014). Por exemplo, durante o trabalho de campo me deparei com um caso exemplar em uma jira, quando anotei um ponto cantado alusivo a Maria Padilha que sofreu pequenas alterações, possivelmente, para suavizar seu impacto da associação com o diabo. O ponto que na casa X relatava que A Padilha é a mulher de Lucifer, passou a ser cantado, na casa Y, da seguinte maneira: A Padilha é a mulher de Luz e Fé.

Outro elemento em comum que abarca as práticas dos especialistas regionais, pode ser pensado como a unidade na diversidade, ou seja, percebe-se uma certa autonomia litúrgica e ritual vivida por cada uma das casas religiosas de matrizes afro-brasileiras da região. Mais uma característica pontual diz respeito ao lugar de Exu no terreiro. É imprescindível ressaltar a importância de saber conduzir e ser por ele conduzido para o bom andamento dos trabalhos. A proeminência no conjunto ritual dá o tom do respeito e obediência a Exu na totalidade das casas visitadas. Da perspectiva das práticas sociais, a maior parte dos trabalhos mediúnicos requisitados pelos consulentes está associada ao binômio saúde-doença. Com as preces, passes e os banhos de ervas, entre outras técnicas de cura, receitados pelas entidades em transe, as casas umbandistas acabam colocando em movimento uma espécie de medicina alternativa. Entretanto, as temáticas referentes às relações amorosas e a problemas financeiros (manutenção de emprego, aprovação em concurso público etc.), mesmo que em menor escala, ainda parecem pontuar os trabalhos em todos os terreiros.

Se por um lado, as casas observadas continuam a se apresentar como centros irradiadores de relações simbólicas, sociais e econômicas, por outro, eles não figuram mais quantitativamente como nos tempos do trabalho de campo das antropólogas Yvonne Maggie e Márcia Contins, em uma Baixada Fluminense (RJ), em que eram identificados "quase dois terreiros por rua" (MAGGIE; CONTINS, 1980, p. 79). É certo que houve um encolhimento não só em números absolutos das células religiosas de matrizes afro-brasileiras, bem como se sabe que parte de seus 
adeptos migraram para denominações evangélicas pentecostais e neopentecostais. Todavia, os minúsculos $0,3 \%$ de adeptos das religiões de matrizes afro-brasileiras, que o IBGE conseguiu enxergar nos recenseamentos das últimas décadas, não coincidem com a realidade da microrregião de Cataguases. Basta contarmos o número de médiuns participantes em cada uma das casas, deixando de lado os consulentes, para constatarmos um percentual de adesão muito superior ao supracitado. Enfim, apesar de não possuírem a visibilidade dos cristãos e a continuarem a sofrer com insultos e julgamentos enviesados desferidos de todas as partes, as lideranças religiosas continuam a ressoar seus tambores e dão prosseguimento ao incessante processo de reinvenção de uma prática que pode significar para muitos excluídos de uma sociedade a possibilidade de experimentar e compreender o que é protagonismo.

\section{REFERÊNCIAS}

BERGER, Peter L.; LUCKMANN, Thomas. A construção social da realidade: tratado de sociologia do conhecimento. Petrópolis: Vozes, 2008.

BIRMAN, Patrícia. O campo da nostalgia e a recusa da saudade: temas e dilemas dos estudos afro-brasileiros. Religião e Sociedade, 18(2), p. 75-92, 1997.

CAMURÇA, Marcelo Ayres. A realidade das religiões no Brasil no Censo do IBGE-2000. In: FAUSTINO, Teixeira; MENEZES, Renata (Orgs.). As religiões no Brasil: continuidades e rupturas. Petrópolis: Vozes, 2006. p. 35-48.

CLIFFORD, James; MARCUS, Georges (Orgs.). A escrita da cultura. Poética e política da etnografia. Rio de Janeiro: EDUERJ, 2016.

COSTA, Levy Simões da. Cataguases centenária: dados para sua história. Cataguases: Edição do Autor, 1977.

D'ADESKY, Jacques. Pluralismo Étnico e Multiculturalismo. Racismos e anti-racismos no Brasil. Rio de Janeiro: Pallas, 2009.

DEAN, Warren. A ferro e fogo: a história e a devastação da Mata Atlântica brasileira. São Paulo: Companhia das Letras, 1996.

FONSECA, Denise Pini Rosalem; GIOCOMINI, Sonia Maria. Presença do Axé. Mapeando terreiros no Rio de Janeiro. Rio de Janeiro: EdPUC, 2013.

LAPLANTINE, François; RABEYRON, Paul-Louis. Medicinas paralelas. São Paulo: Brasiliense, 1989. 
LEISTNER, Rodrigo Marques. Os outsiders do além: um estudo sobre a quimbanda e outras 'feitiçarias' afro-gaúchas. 2014. 388 f. Tese (Doutorado em Ciências Sociais) - Universidade do Vale do Rio dos Sinos, São Leopoldo, 2014.

LUZ, Marco Aurélio. Cultura negra e ideologia do recalque. Salvador: EDUFBA; Rio de Janeiro: Pallas, 2011.

MAGGIE, Yvonne. Medo do feitiço: relações entre magia e poder no Brasil. Rio de Janeiro: Arquivo Nacional, 1992.

MARCUS, George E. O intercâmbio entre arte e antropologia: como a pesquisa de campo em artes cênicas pode informar a reinvenção da pesquisa de campo em antropologia. Revista de Antropologia, São Paulo, v. 47, n. 1, 2004. p. 133-158.

MONTERO, Paula. Da doença à desordem: a magia na umbanda. Rio de Janeiro: Graal, 1985.

MONTERO, Paula. Controvérsias religiosas e Esfera Pública: repensando as religiões como discurso. Religião \& Sociedade, v. 32, p. 15-30-30, 2012.

NASCIMENTO, Abdias do. O genocídio do negro brasileiro. Processo de um racismo mascarado. Rio de Janeiro: Paz e Terra, 1978.

NOGUEIRA, Natania Aparecida da Silva; SILVA, Lucilene Nunes da. Uma viagem no tempoLeopoldina: povoamento, café e atualidades. Leopoldina: [S/N], 2008.

ORTIZ, Renato. A moderna tradição brasileira. São Paulo: Brasiliense, 1988.

ORTIZ, Renato. A morte branca do feiticeiro negro. Umbanda e sociedade brasileira. São Paulo: Brasiliense, 1999.

PIERUCCI, Antônio Flávio. Religião como solvente: uma aula. Novos Estudos CEBRAP, n. 75, p. 111-127, 2006.

PRANDI, Reginaldo. As religiões afro-brasileiras nas ciências sociais: uma conferência, uma bibliografia. Revista Brasileira de Informação Bibliográfica em Ciências Sociais, BIB-ANPOCS, São Paulo, n. 63, p. 7-30, 2007.

PRANDI, Reginaldo. De africano a afro-brasileiro: etnia, identidade, religião. In: PEREIRA, Edmilson de Almeida; DAIBERT JÚNIOR, Robert (Orgs.). Depois, o Atlântico. Modos de pensar, crer e narrar na diáspora africana. Juiz de Fora: Ed. UFJF, 2010. p. 19-37.

SILVA, Vagner Gonçalves da (Org.). Intolerância religiosa. Impactos do neopentecostalismo no campo religioso afro-brasileiro. São Paulo: Edusp, 2007. 
TEIXEIRA, Talita Bender. Trapo formoso: o vestuário na quimbanda. 2005. 126 f. Dissertação (Mestrado em Antropologia Social) - Universidade Federal do Rio Grande do Sul, Porto Alegre, 2005.

VAINFAS, Ronaldo. Quimbanda. In: VAINFAS, Ronaldo (Org.). Dicionário do Brasil Colonial: (1500-1808). Rio de Janeiro: Objetiva, 2001. p. 496-497.

Recebido em: 08 de abril de 2020

Aceito em: 09 de junho de 2020 